\title{
FLOW PATTERNS OF THE ESTER OIL-REFRIGERANT R134A MIXTURE FLASHING FLOW THROUGH A SMALL DIAMETER TUBE
}

\author{
H. O. S. Castro, \\ J. L. Gasche, \\ W. P. Conti, \\ and E. D. R. Vieira \\ UNESP- Campus de Ilha Solteira \\ Departamento de Engenharia Mecânica \\ Avenida Brasil Centro 56, \\ Ilha Solteira, São Paulo, Brasil \\ heryca@dem.feis.unesp.br \\ gasche@dem.feis.unesp.br \\ conti@dem.feis.unesp.br \\ delrio@dem.feis.unesp.br \\ D inner diameter of the tube, $m$ \\ f friction factor, dimensionless \\ Re Reynolds number, dimensionless \\ $\mathrm{Z}$ longitudinal coordinate, $\mathrm{m}$
}

\section{ABSTRACT}

This work presents an experimental investigation of the ester oil ISO VG10refrigerant R134a mixture flashing flow with foam formation through a straight horizontal $3.22 \mathrm{~mm}$-diameter- $6.0 \mathrm{~m}$ - long tube. An experimental apparatus was designed to allow the measurement of both pressure and temperature profiles along the tube as well as the visualization of the flow patterns. Tests were performed at different mass flow rates, several refrigerant mass fractions at the inlet of the flow, and inlet mixture temperatures around 28 and $39{ }^{\circ} \mathrm{C}$. A liquid mixture flow with constant temperature and pressure gradient could be noticed at the inlet of the tube. As the flow proceeded towards the exit of the tube the pressure drop produced a reduction of the refrigerant solubility in the oil yielding to formation of the first bubbles. Initially, small and few bubbles could be noticed and the flow behaved as a conventional two-phase flow. Eventually, the bubble population increased and foam flow was observed at the exit of the tube. Due to the great formation of bubbles, both the temperature and pressure gradient of the mixture were greatly reduced in this region of the flow.

Keywords: compressor, oil-refrigerant mixture, flashing flow, foam

\section{NOMENCLATURE}

$\mathrm{p}$ pressure, bar

$\overline{\mathrm{V}} \quad$ average velocity, $\mathrm{m} / \mathrm{s}$

\section{Greek symbols}

$\rho \quad$ density, $\mathrm{kg} / \mathrm{m}^{3}$

$\mu \quad$ absolute viscosity, N.s $/ \mathrm{m}^{2}$

\section{INTRODUCTION}

Regarding to the refrigeration cycle a good miscibility of the refrigerant in the lubricating oil is required in order to allow easy return of circulating oil to the compressor through the reduction of the oil viscosity. However, inside the compressor this miscibility considerably modifies the leakage of the refrigerant gas through the clearances, the lubrication of sliding parts, and the performance of journal bearings. The solubility of the refrigerant in the lubricating oil depends on the oil temperature and refrigerant vapor pressure, reducing as the temperature increases or the pressure decreases. Consequently, as the mixture flows through the several types of channels inside the compressor there will be formation of refrigerant gas bubbles (outgassing) due to the reduction of the solubility caused by the friction pressure drop. Calvert (1990) has shown that the behavior of this flashing flow is much different from the conventional two-phase flows (bubbly, slug, annular) as the void fraction reaches values typically of about 0.7 (Winkler et al., 1994), where foam flow is generally observed. Therefore, a general understanding of the oilrefrigerant mixture flashing flow with foam formation through small channels is crucial in order to develop a knowledge basis onto which lubrication and gas leakage models can be built.

Mainly in the 80's and 90's, several works related to oil-refrigerant mixture started being developed. Some of these works were directed towards the determination of the themophysical properties of the new mixtures (Martz et al.; 1996, Grebner and Crawford., 1993; Thomas and Pham, 1992; Baustian et al., 1986; Thome, 1995; and Van Gaalen et al., 1990, 1991a, 1991b). Other researchers concentrated their studies on the behavior of refrigerant flows contaminated with lubricating oil with the objective of analyzing the influence of the oil in the mixture flow and heat transfer dynamics in evaporators and condensers. Some examples of these researchers are Schlager et al. (1987), Jensen and Jackman (1984), Wallner and Dick (1975) Hambraeus (1995) and Mitrovic (1998).

Motta et al. (2001) have provided a good literature review on oil-refrigerant mixture flows. From this work, one could notice that most of the researches were related to mixture flows with low oil 
mass fraction (less than 5\%), that is, the oil was treated as the contaminant.

There have been very few studies of oilrefrigerant flow in which the oil was contaminated by the refrigerant. Lacerda et al. (2000) have presented an experimental research on oil-refrigerant two-phase flow through a long tube using mineral oil and R12 as refrigerant. They measured pressure and temperature profiles of the flow through a $2.86 \mathrm{~mm}$-diameter Bundy type tube. Furthermore, they visualized the flow patterns of the same mixture flowing through a $3.03 \mathrm{~mm}$-diameter glass tube. The visualization results showed a foam flow at the end of the tube, where they obtained a great reduction in both temperature and pressure. Poiate Jr. and Gasche (2002) obtained similar pressure and temperature distribution for the same mixture flowing through a $3.22 \mathrm{~mm}$-diameter Bundy type tube, and visualization results for the flow through a $3.0 \mathrm{~mm}$-diameter glass tube. The results were qualitatively the same.

Recently, Barbosa Jr. et al. (2004) have presented an analysis of the available prediction methodologies for frictional pressure drop in twophase gas-liquid flows of oil-rich refrigerantlubricant oil mixtures in a small diameter tube. Several correlations and methods to calculate the frictional two-phase pressure drop were investigated by the authors, some of them being state-of-art methods developed based on data for small diameter channels. They found none of the methodologies performed satisfactorily over the range conditions covered during R12-mineral oil mixture flow tests in a $5.3 \mathrm{~m}$ long, $2.86 \mathrm{~mm}$ diameter tube.

This research was undertaken to study the behavior of the flashing flow of a mixture composed by R134a and refrigerant ester oil ISO VG10 using the same apparatus utilized by Poiate Jr. and Gasche (2002), focusing on the flow patterns of the flow. It will be presented results for some pressure and temperature distribution along the flow through a $6 \mathrm{~m}$-long, $3.2 \mathrm{~mm}$-diameter tube, as well as the flow pattern visualization results.

\section{EXPERIMENTAL METHOD - APPARATUS AND INSTRUMENTATION}

The experimental apparatus was designed to produce steady flows of the oil-refrigerant mixture through two $6 \mathrm{~m}$ long tubes in such a way that three types of flow patterns could be observed along the flow: a liquid mixture flow at the entrance of the tube, an intermediary two-phase region, and a foam flow in a region near the end of the tube. One metallic Bundy type tube was instrumented with pressure transducers and thermocouples in order to measure the pressure and temperature distribution along the flow. A glass tube was used to allow the visualization of the flow patterns.

A general view of the experimental apparatus is shown in Fig. 1. Basically, four tanks, a test section, a vapor return line, an oil return line, instrumentation, and a data acquisition system compose the experimental apparatus. All these equipments are connected with each other in order to produce the flow through either of two $6 \mathrm{~m}$ long horizontal tubes, which consist the test section. The first tube is made of borosilicate glass (3.0 mm ID) and allows flow visualization. The other tube is a metallic Bundy type $3.22 \mathrm{~mm}$ ID $( \pm 0.03)$ equipped with 10 pressure transducers $( \pm 2 \mathrm{kPa})$ and 15 type $\mathrm{T}$ thermocouples $( \pm$ $0.5^{\circ} \mathrm{C}$ ) installed along the tube surface. The experimental apparatus runs on the blow down mode.

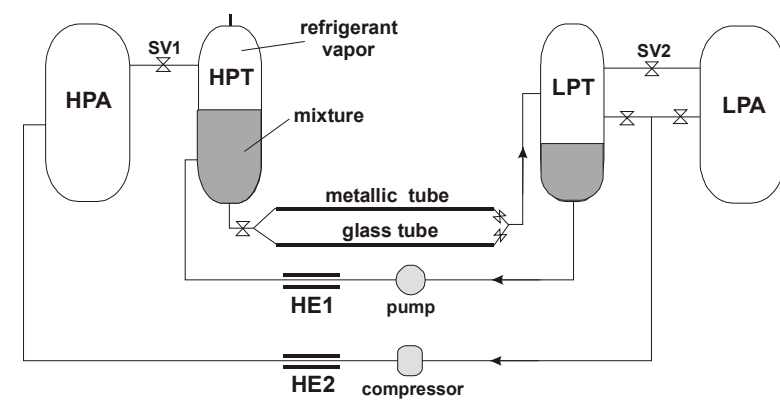

Figure 1. Experimental apparatus

The main objective of the four tanks is to maintain constant the pressure difference between the high and low-pressure tanks (HPT, LPT). The HPT is filled with oil and refrigerant, and an equilibrium liquid mixture at the bottom of the tank coexists with the refrigerant vapor at the top for desired temperature and vapor pressure. Pressure and temperature sensors monitor the conditions of the vapor and liquid in both tanks. High and low pressure accumulators (HPA, LPA) operating at pressures higher and lower than those at HPT and LPT respectively, keep the pressure at constant levels in both tanks using two automatic solenoid valves controlled by a desktop computer. During operation the equilibrium liquid mixture existing in HPT is driven into either of the two tubes.

Auxiliary equipment consists of a compressor, an oil pump, and two heat exchangers (HE1, HE2). The compressor is employed to return the gas to the HPA and the pump returns the oil back to the HPT. The heat exchangers are used to cool both fluids if necessary before reaching the HPA and HPT. Sensors data allow monitoring of flow conditions and were imputed into a PC-based data acquisition system. All instruments were calibrated using the data acquisition system.

\section{EXPERIMENTAL PROCEDURE}

Firstly, the necessary parts of the apparatus were flushed with a solvent fluid to remove impurities and the system was evacuated to $10 \mathrm{~Pa}$. After that, $80 \mathrm{~kg}$ of ester oil ISO VG10 was put into the HPT and heated until $60^{\circ} \mathrm{C}$ for three hours to 
facilitate humidity removal while the vacuum pump was kept running. Next, $60 \mathrm{~kg}$ of R-134a was put partly into both the HPT and HPA.

All tests started with the saturation of the oil in the HPT at the desired test temperature and 100 mbar above the desired pressure, that is, at $\mathrm{p}_{\mathrm{i}}=\mathrm{p}_{\mathrm{t}}+100$ mbar. In order to increase the rate of abortion the refrigerant was circulated in the HPT by employing the compressor to drive the refrigerant gas from the top and compressing it at the bottom of the HPT. As gas is absorbed by the liquid mixture, the pressure tends to decrease, activating the automatic solenoid valve (SV1) which releases refrigerant from HPA to HPT in order to maintain the pressure in the HPT constant. This process continues until saturation is achieved in the HPT at $\mathrm{p}_{\mathrm{i}}$. The saturation process could last until six hours. After saturation is reached at $\mathrm{p}_{\mathrm{i}}$ some amount of gas is released from the top of HPT to decrease the pressure to $p_{t}$, the desired test pressure. This pressure reduction promotes a fast outgassing and assures that saturation was indeed established at pressure $p_{t}( \pm 1 \%$ of the value). This new saturation state is reached within 30 to 60 minutes, which is observed when pressure stops increasing because of gas release. In all this processes the temperature is controlled at the desired value $\left( \pm 1^{\circ} \mathrm{C}\right)$.

Depending whether flow visualization or measurement run is desired, after the saturation process is finished the test section valves are arranged so that the mixture is forced into the glass or the Bundy tube, respectively. During the experimental runs the compressor remain running in order to circulate gas from the LPA to the HPA. Data acquisition is initiated after the steady flow is reached.

Prior to initiating the experiments with mixtures, some tests were performed with pure oil flow in the Bundy type tube and nitrogen to pressurize the tanks and accumulators. These tests were used for evaluating and validating the experimental loop, instrumentation, and data acquisition. In addition, they validated the methodology to obtain the mass flow rate of the mixture flows, which was based on the use of the linear pressure gradient established at the inlet of the tube when the flow was still a liquid mixture flow. Details about the validation of the experimental apparatus can be found in Poiate Jr. (2001).

\section{DATA REDUCTION AND INTERPRETATION}

In order to avoid outgassing before the liquid mixture reaches the tube, a mass flow meter was not used to obtain the mass flow rate. Instead, the mass flow rate was calculated by using the linear pressure gradient measured at the entrance of the tube, where the mixture was still in the liquid state and the flow was completely developed. The average velocity used to determine the mass flow rate was calculated using Equation (1):

$$
\bar{V}=\left[\frac{2 \mathrm{D}}{\rho \mathrm{f}}\left(-\frac{\mathrm{dp}}{\mathrm{dz}}\right)\right]^{1 / 2}
$$

where $\mathrm{D}$ is the inner diameter of the tube, $\mathrm{m} ; \rho$ is the density calculated at the inlet temperature of the mixture, $\mathrm{kg} / \mathrm{m}^{3}$; $\mathrm{f}$ is the friction factor calculated by the equation proposed by Churchill (1977), and dp/dz is the pressure gradient along the flow direction measured at the linear portion of the pressure distribution, $\mathrm{Pa} / \mathrm{m}$.

The Reynolds number was defined as

$$
\operatorname{Re}=\frac{\rho \overline{\mathrm{V} D}}{\mu}
$$

where $\mu$ is the absolute viscosity of the liquid mixture at the inlet of the tube, N.s $/ \mathrm{m}^{2}$. Both properties, $\mu$ and $\rho$, were given by the oil manufacturer. In addition, the saturation mass fraction of the refrigerant in the oil, w, was also taken from the oil manufacturer.

The uncertainties of the reduced data were determined by propagating the measurement uncertainties using standard methods (Moffat, 1988). The uncertainty of the average velocity was $\pm 5 \%$, while the uncertainty of the Reynolds was $\pm 10 \%$. The uncertainty of the average velocity depends on the pressure gradient at the inlet of the flow and was estimated by the uncertainty of the pressure curve fitting accomplished in that region taking in account the uncertainties of the temperature and pressure.

\section{RESULTS AND DISCUSSION}

Pressure and temperature profiles were measured and visualization results were obtained for more than 30 tests, but only some of the results are shown in this paper. Temperatures at the inlet of the flow were about 28 and $39{ }^{\circ} \mathrm{C}$. For temperatures around $28{ }^{\circ} \mathrm{C}$, the saturation pressures inside the HPT were 4.0 and 5.0 bar, while for temperatures around $39{ }^{\circ} \mathrm{C}$ the pressure saturation was 5.0 bar. These saturation pressures were chosen in such a way that foam flow could be observed at the exit region of the tube. All those tests were undertaken using a mixture composed by an ester oil ISO VG10 and refrigerant R134a.

The Figures 3 to 6 present the visualization results for the test shown in Fig. 2, whose inlet pressure, temperature and concentration were $4.0 \mathrm{bar}$, $27.5^{\circ} \mathrm{C}$, and $35 \%$ respectively. These figures depict several photographs taken in the same position at different instants. In Figure 3, where $\mathrm{z}=2.26$ to $\mathrm{z}=$ $2.36 \mathrm{~m}$, the first photograph shows small vapor bubbles grouped together flowing among liquid films located on the tube wall. In the second photograph, some of these bubbles agglomerate, forming larger bubbles. As could be expected, the bubbles tend to 


\section{Ciência/Science}

flow mainly in the upper portion of the tube due to the buoyancy effect.

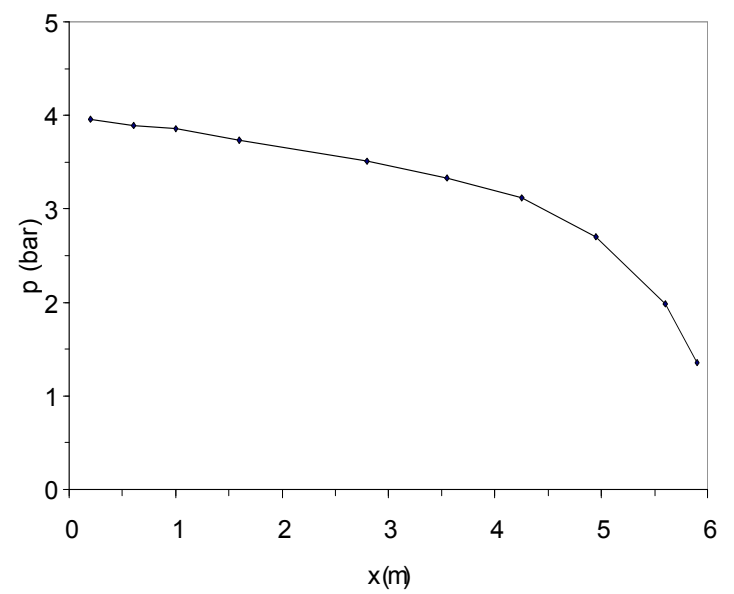

(a)

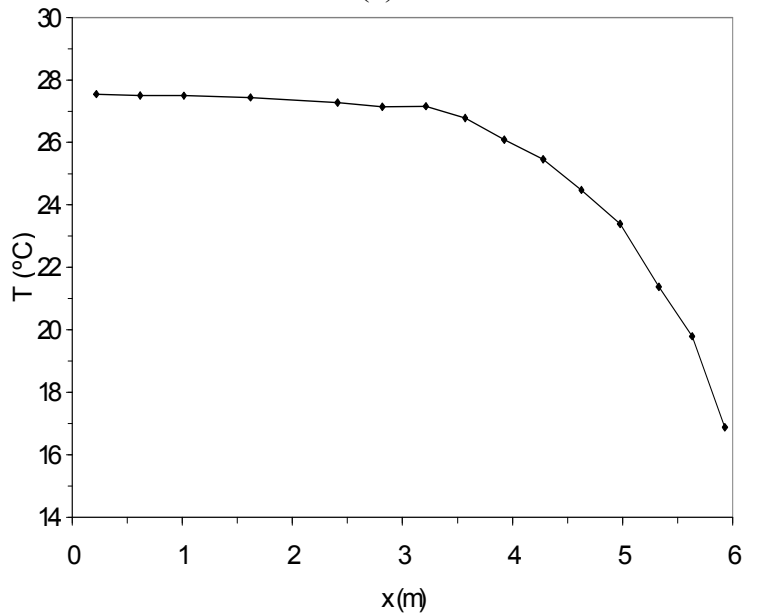

(b)

Figure 2. Results for $\mathrm{Re}=2400$-test, whose inlet pressure was 4.0 bar, inlet temperature was around $27.5^{\circ} \mathrm{C}$, and mass fraction was $35 \%$ : (a) Pressure profile, (b) temperature profile.

Figure 4 shows the flow patterns visualized in the region located from $\mathrm{z}=3.004$ to $3.130 \mathrm{~m}$. As can be seen, several flow patterns were found in this region. The first photograph shows small single bubbles flowing in line, while the second and third photographs depict two types of configuration: some regions containing many tiny bubbles grouped together and other regions with long bubbles. The fourth photograph shows similar patterns with greater number of tiny bubbles. In this region of the flow the pressure and temperature start decreasing. It can be also notice that the flow regime was intermittent.

Figure 5, where was $\mathrm{z}=4,37$ to $\mathrm{z}=4,47 \mathrm{~m}$, one can observe more uniform flow patterns, that is, it seems that the void fraction increasing due to the larger reduction of the solubility of the mixture reduces the intermittency of the flow. It is observed that the refrigerant in the vapor state already occupies most part of the tube, mainly in the third photograph,
Castro et al. Flow Patterns of the Ester Oil-Refrigerant...

where the bubbles cannot be identified. In this case, the flow pattern is similar to foam.

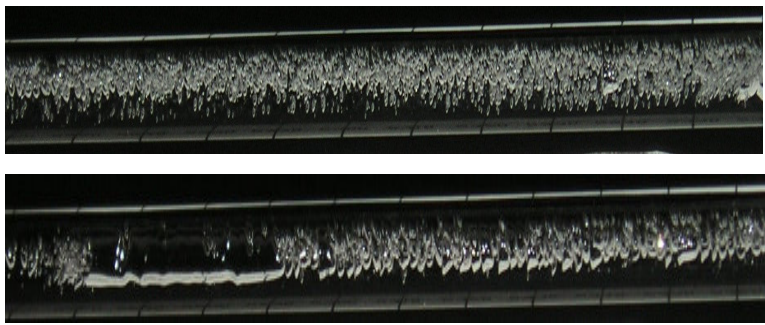

Figure 3. Flow patterns in the region from $\mathrm{z}=2.260$ to $2.360 \mathrm{~m}$ for $\mathrm{Re}=2400$-test, whose inlet pressure was

4.0 bar, inlet temperature was $27.5^{\circ} \mathrm{C}$, and inlet refrigerant mass fraction was $35 \%$.

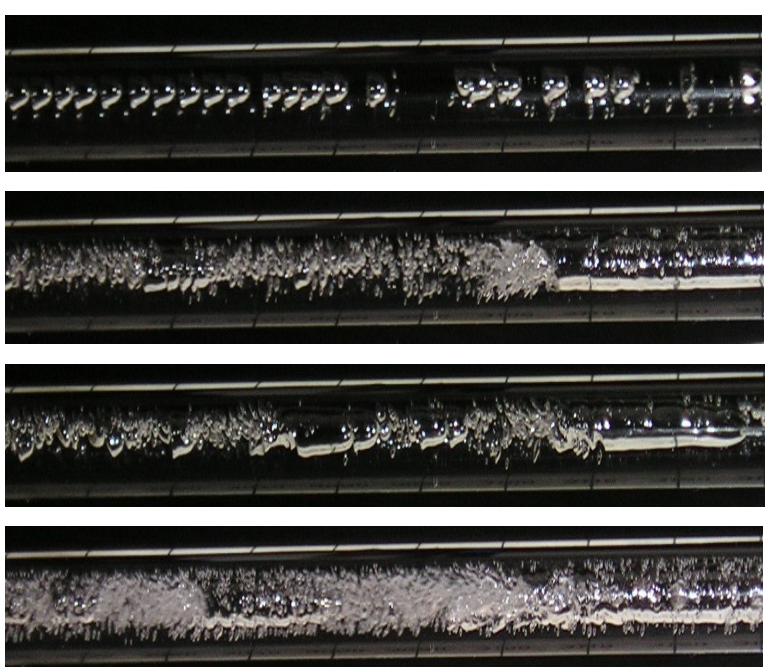

Figure 4. Flow patterns in the region from $z=3.004$ to $3.130 \mathrm{~m}$ for $\mathrm{Re}=2400$-test, whose inlet pressure was 4.0 bar, inlet temperature was $27.5^{\circ} \mathrm{C}$, and inlet refrigerant mass fraction was $35 \%$.
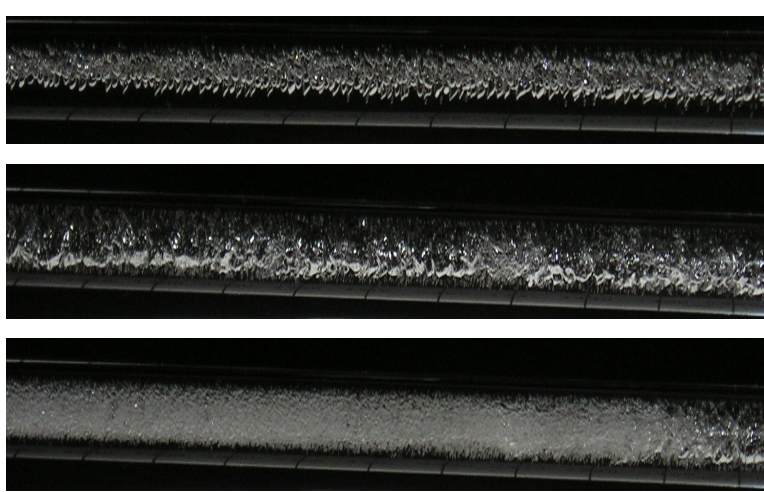

Figure 5. Flow patterns in the region from $z=4.370$ to $4.470 \mathrm{~m}$ for the $\mathrm{Re}=2400$-test, whose inlet pressure was 4.0 bar, inlet temperature was $27.5^{\circ} \mathrm{C}$, and inlet refrigerant mass fraction was $35 \%$.

Figure 6 shows that at the end of the tube, from $\mathrm{z}=5.73$ to $5.83 \mathrm{~m}$, only the foam flow pattern can be encountered as the void fraction increases. In this 


\section{Ciência/Science}

case, however, the vapor phase occupies the entire cross section of the tube. It is worthy noting that this type of flow pattern is not usually found in two-phase flows of refrigeration systems.

Although not shown here, single-phase flow is always observed at the inlet of the tube.

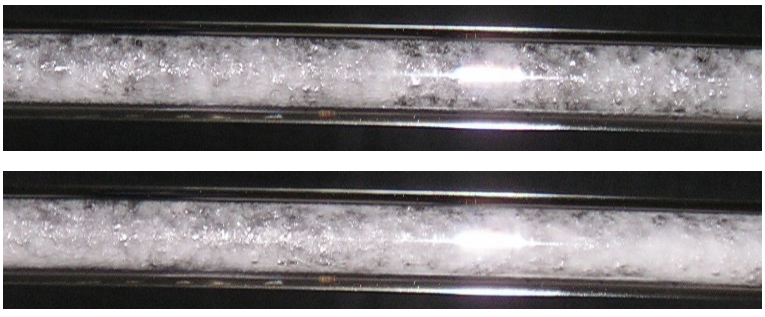

Figure 6. Flow patterns in the region from $\mathrm{z}=5.730$ to $5.830 \mathrm{~m}$ for the $\mathrm{Re}=2400$-test, whose inlet pressure was 4.0 bar, inlet temperature was $27.5^{\circ} \mathrm{C}$, and inlet refrigerant mass fraction was $35 \%$.

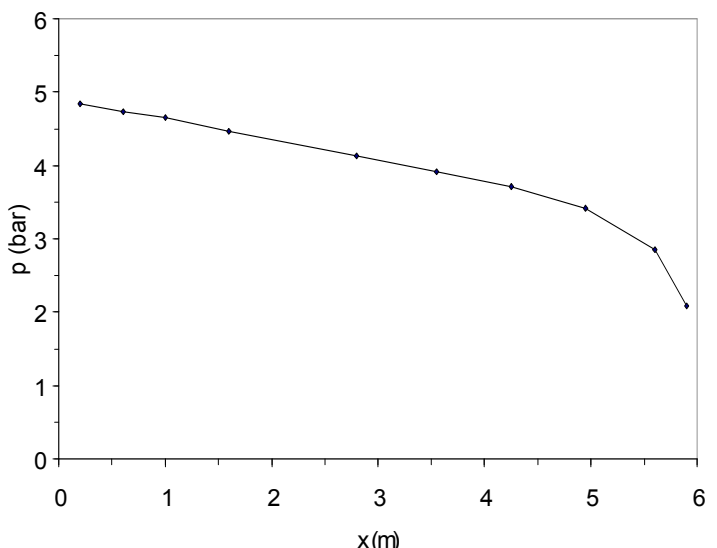

(a)

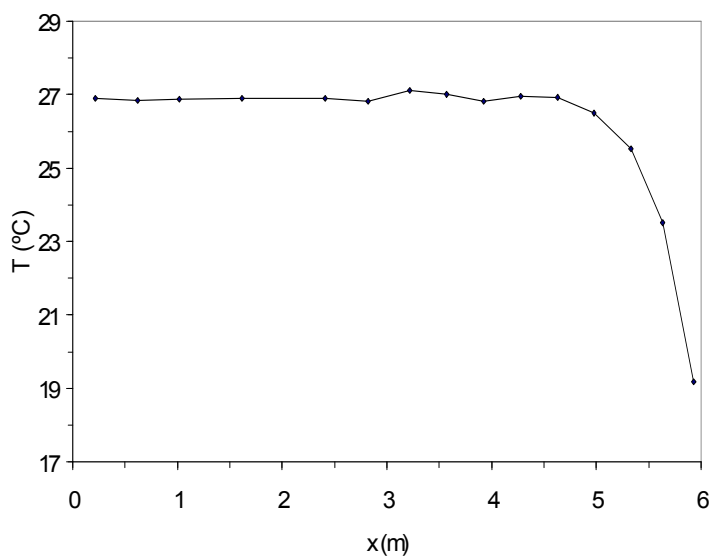

(b)

Figure 7. Results for the $\mathrm{Re}=1400$-test, whose inlet pressure was 5.0 bar, inlet temperature was around $27.0{ }^{\circ} \mathrm{C}$, and mass fraction was $60 \%$ : (a) Pressure profile, (b) temperature profile.

Figures 8 to 10 present the visualization results for the test shown in Fig. 7, whose inlet pressure, temperature and concentration were 5.0 bar, $27.0^{\circ} \mathrm{C}$, and $60 \%$, respectively. The flow characteristics are
Castro et al. Flow Patterns of the Ester Oil-Refrigerant...

similar to those described for the previous test. It is observed, however, that the formation of the first bubbles occurred at a larger $\mathrm{z}$, relating to the previous test. There must be an initial pressure drop in order to nucleate the first bubbles. The larger the pressure drop the sooner the bubble nucleation occurs. As in this test the Reynolds number $(\mathrm{Re}=1400)$ is lower, the bubble nucleation occurs downstream the nucleation position of the previous test.
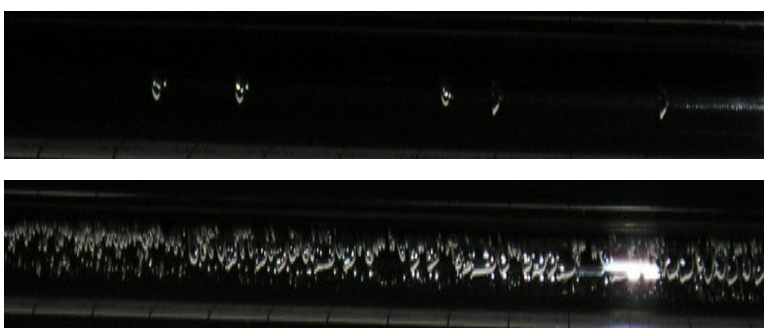

Figure 8. Flow patterns in the region from $z=4.090$ to $4.190 \mathrm{~m}$ for the $\mathrm{Re}=1400$-test, whose inlet pressure was 5.0 bar, inlet temperature was $27.0{ }^{\circ} \mathrm{C}$, and inlet refrigerant mass fraction was $60 \%$.
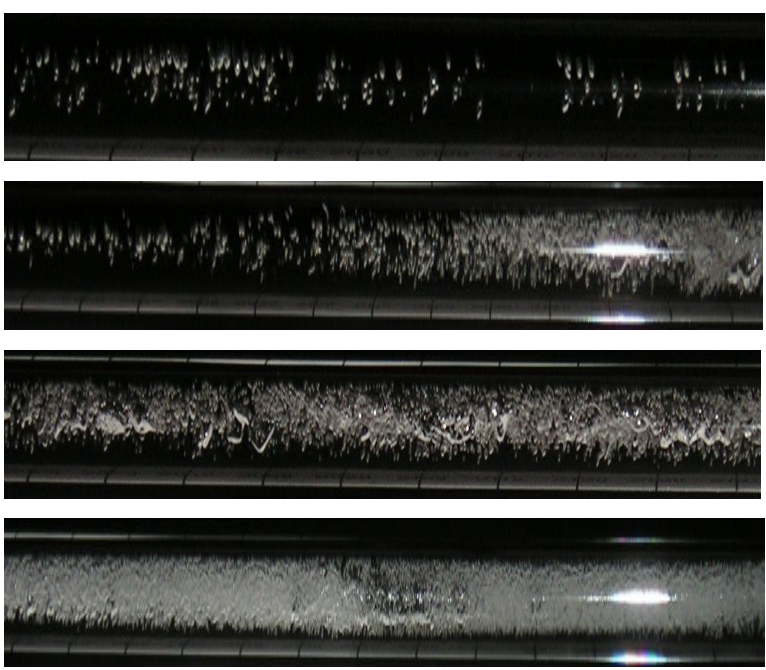

Figure 9. Flow patterns in the region from $z=5.060$ to $5.170 \mathrm{~m}$ for the $\mathrm{Re}=1400$-test, whose inlet pressure was 5.0 bar, inlet temperature was $27.0^{\circ} \mathrm{C}$, and inlet refrigerant mass fraction was $60 \%$.
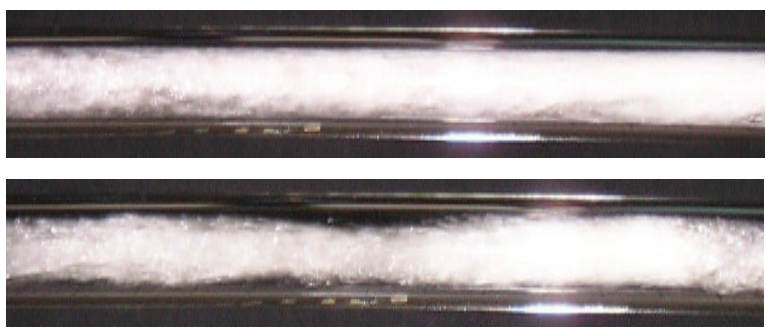

Figure 10. Flow patterns in the region from $\mathrm{z}=5.720$ to $5.830 \mathrm{~m}$ for the $\mathrm{Re}=1400$-test, whose inlet pressure was 5.0 bar, inlet temperature was $27.0^{\circ} \mathrm{C}$, and inlet refrigerant mass fraction was $60 \%$. 
Figures 12 to 15 present the visualization results for the $R e=2300$-test, whose pressure and temperature profiles are shown in Fig. 11. The inlet pressure, temperature, and concentration were 5.0 bar, $38.7{ }^{\circ} \mathrm{C}$, and $22 \%$, respectively. For the position $\mathrm{z}=2.52$ to $2.65 \mathrm{~m}$ (Fig. 12) the photographs show the presence of a great number bubbles grouped together flowing among liquid films.

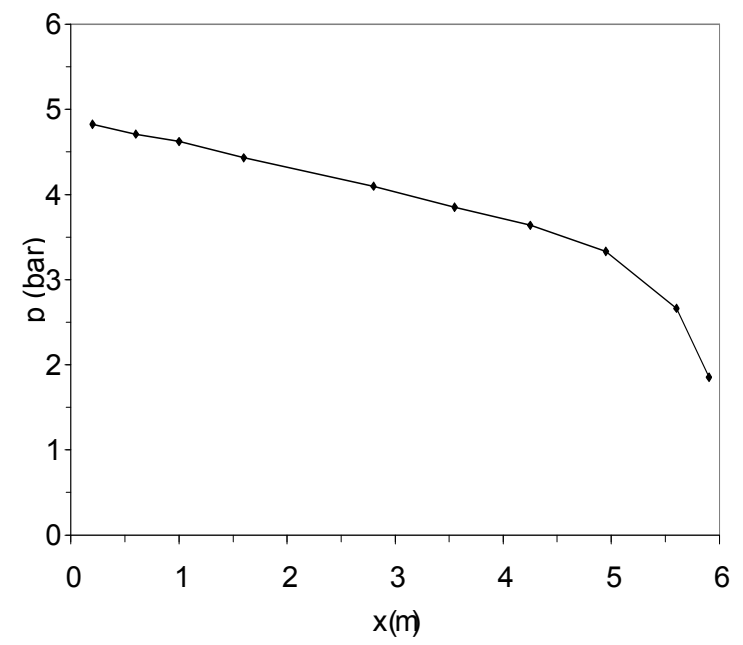

(a)

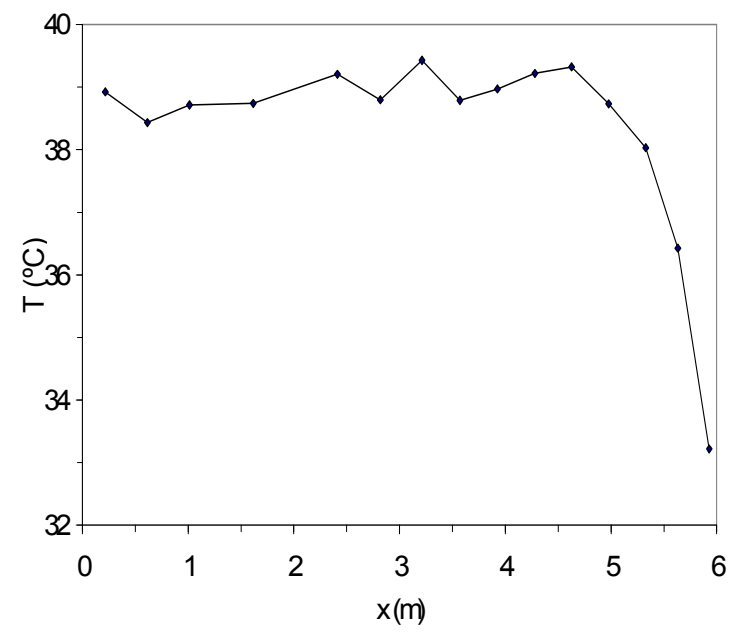

(b)

Figure 11. Results for the $\mathrm{Re}=2300$ - test, whose inlet pressure was 5.0 bar, inlet temperature was around $38.7^{\circ} \mathrm{C}$, and mass fraction was $22 \%$ : (a) Pressure profile, (b) temperature profile.

In Fig. 13, different flow patterns are observed for the region $\mathrm{z}=3.49$ to $3.56 \mathrm{~m}$, which corresponds to the intermediate region of the tube. The first photograph shows small gun bullet bubbles flowing in line in the upper portion of the tube. In the second photograph it is observed that the number of this type of bubble increases. The third photograph shows long bubbles following together with small bubbles. In the left part of the fourth photograph one can notice a larger number of tiny bubbles occupying most part of the tube, and also the presence of larger deformed bubbles in the right side of the photograph. This photograph sequence also can be used to show the intermittent effect of the flow regime, characterized by different flow patterns observed in the same position of the tube.

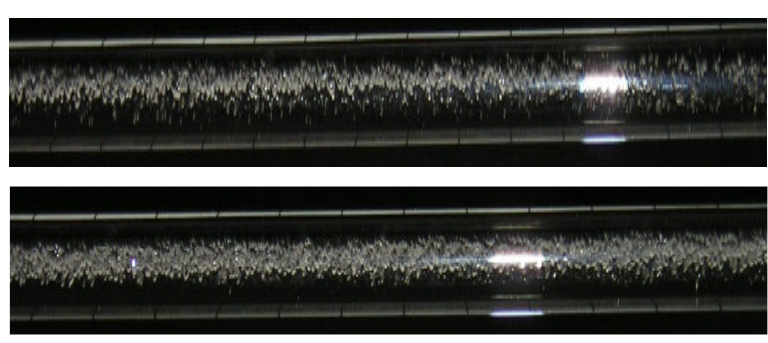

Figure 12. Flow patterns in the region from $\mathrm{z}=2.520$ to $2.650 \mathrm{~m}$ for the $\mathrm{Re}=2300$-test, whose inlet pressure was 5.0 bar, inlet temperature was $38.7^{\circ} \mathrm{C}$, and inlet refrigerant mass fraction was $22 \%$.
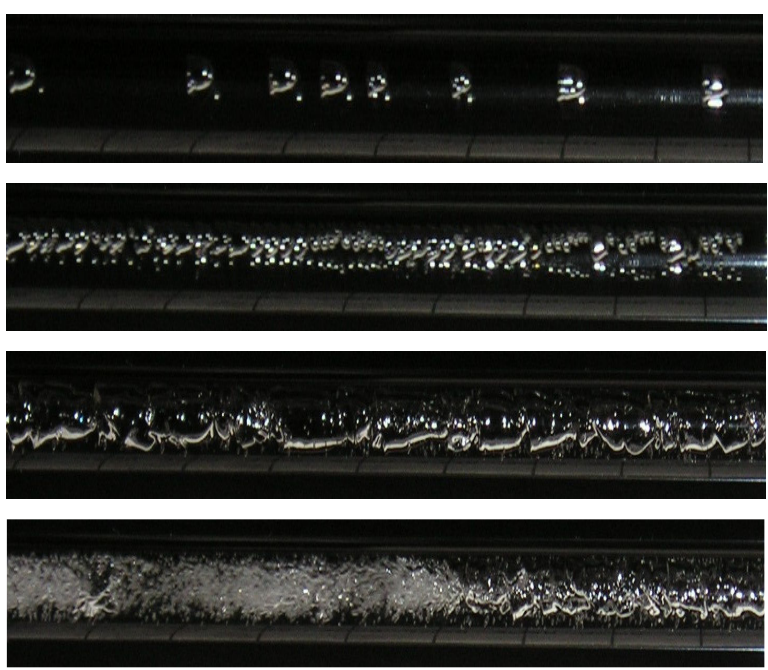

Figure 13. Flow patterns in the region from $z=3.490$ to $3.560 \mathrm{~m}$ for the $\mathrm{Re}=2300$-test, whose inlet pressure was 5.0 bar, inlet temperature was $38.7^{\circ} \mathrm{C}$, and inlet refrigerant mass fraction was $22 \%$.

For $\mathrm{z}=4.55$ to $4.65 \mathrm{~m}$ (Fig. 14) the photographs show a larger number of small bubbles grouped together, apparently already characterizing the foam flow pattern. Figure 15 shows the visualization results at the exit of the tube, for $\mathrm{z}=5.75$ to $5.83 \mathrm{~m}$. The pictures show that the foam flow pattern is predominant. In this region occurs a great pressure and temperature reduction, as shown in Fig. 11.

It is important to stand out the intermittent aspect of the flow. Except at the exit region of flow, where the foam flow pattern is visualized, it is observed different flow patterns in the same position of the tube in all accomplished tests. As already commented previously, the causes of the intermittent regime are still unknown. 

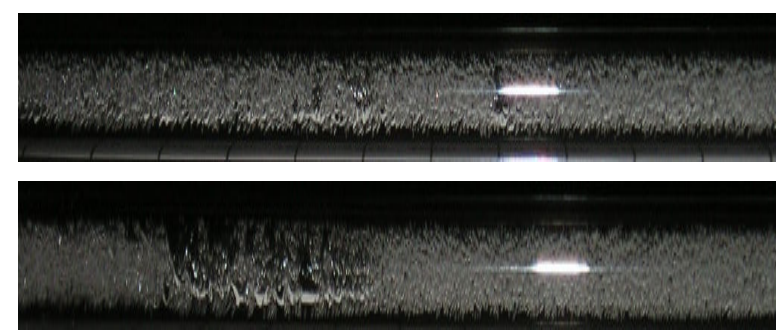

Figure 14. Flow patterns in the region from $\mathrm{z}=4.550$ to $4.650 \mathrm{~m}$ for the $\mathrm{Re}=2300$-test, whose inlet pressure was 5.0 bar, inlet temperature was $38.7^{\circ} \mathrm{C}$, and inlet refrigerant mass fraction was $22 \%$.
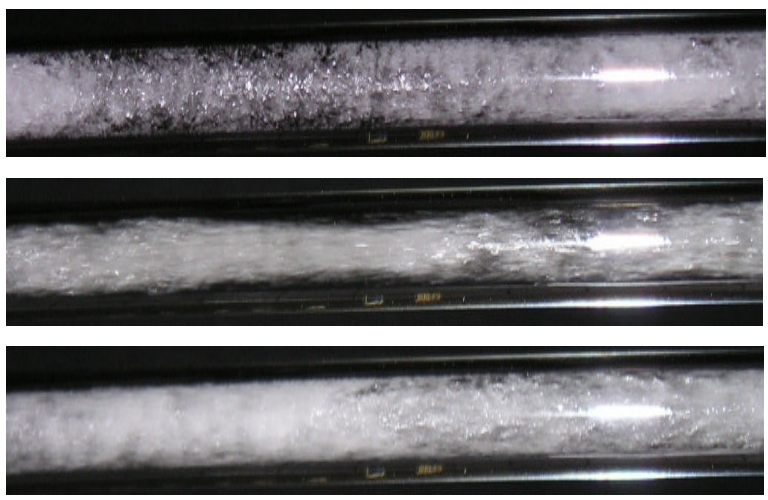

Figure 15. Flow patterns in the region from $\mathrm{z}=5.750$ to $5.830 \mathrm{~m}$ for the $\mathrm{Re}=2300$-test, whose inlet pressure was 5.0 bar, inlet temperature was $38.7^{\circ} \mathrm{C}$, and inlet refrigerant mass fraction was $22 \%$.

\section{CONCLUSIONS}

An experimental apparatus was used to study the flashing flow of the ester oil ISO VG10refrigerant R134a mixture flowing through a straight horizontal $3.22 \mathrm{~mm}$-diameter-6.0 m-long tube. The main motivation of the work was to improve the understanding of the flow for developing physical models to be used in analysis and simulation of lubricating and leakage processes occurring inside refrigeration compressors.

Pressure and temperature distribution along the flow were measured for inlet temperatures around 28 and $39{ }^{\circ} \mathrm{C}$, and inlet pressures of 4.0 and 5.0 bar. A liquid mixture flow with constant temperature and pressure gradient could be seen at the inlet of the tube. As the flow proceeded towards the exit of the tube the pressure drop produced a reduction of the refrigerant solubility in the oil yielding to formation of bubbles. Initially, small and few bubbles could be noticed and the flow behaved as a conventional twophase flow. Eventually, the bubble population increased and foam flow was observed at the exit of the tube. Due to the great formation of bubbles, both temperature and pressure gradient of the mixture were greatly reduced in this region of the flow. Visualization results also showed that the flow regime was intermittent.

\section{ACKNOWLEDGEMENTS}

This research was supported by FAPESP-São Paulo State Research Foundation.

\section{REFERENCES}

Barbosa Fr., J. R., Lacerda, V. T. and Prata, A. T., 2004, Prediction of pressure drop in refrigerantlubricant oil flows with high contents of oil and refrigerant outgassing in small diameter tubes, Int. J. Refrig., Vol. 27, pp. 129-139.

Baustian, J. J., Pate, M. B. and Bergles, A. E., 1986, Properties of oil-refrigerant mixtures liquid with applications to oil concentration measurements: part I - thermophysical and transport properties," ASRHAE Transactions, Vol. 92, pp. 55-73.

Calvert, J. R., 1990, Pressure drop for foam flow through pipes, Int. J. Heat and Fluid Flow, Vol. 11 No. 3, pp.236-241.

Churchill, S. W., 1977, Friction-factor equation spans all fluid-flow regimes, Chem. Eng., Vol. 7, pp. 91-92.

Grebner, J. J. and Crawford, R. R., 1993, Measurement of pressure temperature-concentration relations for mixtures of R12/mineral oil and R134a synthetic oil, ASHRAE Transactions, Vol. 99, Part 1, pp. 387-396.

Hambraeus, K. 1995, Heat transfer of oilcontaminated HFC134a in a horizontal evaporator, Int. J. Refrig. Vol. 18, No. 2, pp. 87-99.

Jensen, M. K. and Jackman, D. L., 1984, Prediction of nucleate pool boiling heat transfer coefficients of refrigerant-oil mixtures, J. Heat Transfer, Vol. 106, pp. 184-190.

Lacerda, V. T., Prata, A. T. and Fagotti, F., 2000, Experimental Characterization of oil-refrigerant twophase flow, Prof. ASME-Adv. En. Sys. Div., San Francisco, pp. 101-109.

Martz, W. L., Burton, C. M. and Jacobi, A. M., 1996, Local composition modelling of the thermodynamic properties of refrigerant and oil mixtures, Int. J. Refrig., Vol. 19, No. 1, pp. 25-33.

Mitrovic, J., 1998, Nucleate boiling of refrigerant-oil mixtures: bubble equilibrium and oil enrichment at the interface of a growing vapour bubble, Int. J. Heat Mass Transfer, Vol. 41, pp. 34513467.

Moffat, R. J., 1988, Describing the uncertainties in experimental results, Exp. Thermal Fluid Sci., Vol. 1, pp 3-17.

Motta, S. F. Y., Braga, S. L. and Parise, J. A. R., 2001, Experimental study of adiabatic capillary tubes: critical flow of refrigerant/oil mixtures, HVAC \& R. Research, Vol. 7, pp. 331-344.

Poiate Jr., E., 2001, Two-phase flow of the mineral oil-refrigerant R12 through a straight round tube, MEng. Dissertation (in Portuguese), São Paulo State University, Ilha Solteira-SP, Brazil, 216 p. 
Poiate Jr., E. and Gasche, J. L., 2002, Pressure and temperature distribution and flow visualization of the two-phase mineral oil-R12 mixture (in Portuguese), Brazilian Cong. of Thermal Eng. Sci., paper code CIT02-0843.

Schlager, L. M., Pate, M. B. and Bergles, A. E., 1987, A survey of refrigerant heat transfer and pressure drop emphasizing oil effects and in-tube augmentation, ASHRAE Transactions, Vol. 93, Part 1, pp. 392-415.

Thomas, R. H. P. and Pham, H. T., 1992, Solubility and miscibility of environmentally safer refrigerant/lubricant mixtures, Transactions, Vol. 98, Part 1, pp. 783-788.

Thome, J. R., 1995, Comprehensive thermodynamic approach to modeling refrigerantlubricant oil mixtures, HVAC \& R. Research, Vol. 1, No. 2, pp. 110-126.

Van Gaalen, N. A., Pate, M. B. and Zoz, S. C., 1990, The measurement of solubility and viscosity of oil/refrigerant mixtures at high pressures and temperatures: test facility and initial results for R22/naphthenic oil mixtures, ASHRAE Transactions, Vol. 96, No. 2, pp.183-190.

Van Gaalen, N. A., Zoz, S. C. and Pate, P. E., 1991a, The solubility and viscosity of solutions of R502 in a naphthenic oil and in an alkylbenzene at high pressures and temperatures, ASHRAE Transactions, Vol. 97, No. 2, pp. 100-108.

Van Gaalen, N. A., Zoz, S. C. and Pate, P. E., $1991 \mathrm{~b}$, The solubility and viscosity of solutions of HCFC-22 in a naphthenic oil and in an alkylbenzene at high pressures and temperatures, ASHRAE Transactions, Vol. 97, No. 1, pp. 285-292.

Wallner, R. and Dick, H. G., 1975, Heat transfer to boiling refrigerant-oil mixtures, Proc. Int. Cong. Refrig., Vol. 2, pp. 351-359.

Winkler, W., Valkó, P. P. and Economides, M. J., 1994, Archeological model for polymers foams, Soc. Petroleum Eng., Vol. 3 , pp. 897-906. 